Review Article

\title{
The Effect of Metformin on Polycystic Ovary Syndrome in Overweight Women: A Systematic Review and Meta-Analysis of Randomized Controlled Trials
}

\author{
Yuanyuan Guan, ${ }^{1}$ Dongjun Wang, ${ }^{1}$ Huaien Bu, ${ }^{2}$ Tieniu Zhao, ${ }^{2}$ and Hongwu Wang $\mathbb{D}^{2}$ \\ ${ }^{1}$ Graduate School, Tianjin University of Traditional Chinese Medicine, Tianjin 301617, China \\ ${ }^{2}$ School of Health Sciences and Engineering, Tianjin University of Traditional Chinese Medicine, Tianjin 301617, China \\ Correspondence should be addressed to Hongwu Wang; tjwanghw5555@163.com
}

Received 15 June 2020; Revised 2 August 2020; Accepted 5 September 2020; Published 16 September 2020

Academic Editor: Davide Francomano

Copyright (c) 2020 Yuanyuan Guan et al. This is an open access article distributed under the Creative Commons Attribution License, which permits unrestricted use, distribution, and reproduction in any medium, provided the original work is properly cited.

\begin{abstract}
Objective. Metformin is an important component of PCOS treatment. At present, the effect of metformin in overweight women with PCOS has not been evaluated. Therefore, we conducted a systematic review to assess the effects of metformin in overweight women with PCOS and to analyze the effects of metformin in overweight women with PCOS. Methods. We searched the PubMed, Cochrane Library, Embase, CNKI, VIP, and Wanfang databases for studies published before March 2020. Randomized controlled trials were identified to study the effects of metformin in overweight women with PCOS. Data from studies including body mass index (BMI), waist circumference (WC), follicle-stimulating hormone (FSH), homeostasis model assessment of insulin resistance (HOMA-IR), luteinizing hormone (LH), sex hormone-binding globulin (SHBG), high-density lipoprotein (HDL) cholesterol, low-density lipoprotein (LDL) cholesterol, total cholesterol (TC), triglycerides (TG), fasting blood glucose (FBG), fasting insulin, testosterone, and androstenedione were pooled. Qualified trials were selected, and methodological quality was strictly assessed. Two reviewers chose the studies independently of each other. Results. Twelve trials were included. The intervention group and the control group had significant differences in the changes in body mass index (BMI) (WMD $=-1.25,95 \%$ CI $(-1.60,-0.91)$, $p<0.00001)$ and waist circumference (WC) (WMD $=-1.41,95 \%$ CI $(-2.46,-0.37), p=0.008)$ after metformin. The comprehensive results show that, in all studies, overweight women with polycystic ovary syndrome treated with metformin had significantly improved endocrine and metabolic indicators, including testosterone, follicle-stimulating hormone, luteinizing hormone, and low-density lipoprotein cholesterol. However, metformin did not regulate the secretion indexes of fasting insulin, homeostasis model assessment of insulin resistance, sex hormone-binding globulin, high-density lipoprotein cholesterol, total cholesterol, triglycerides, fasting blood glucose, and androstenedione. Conclusions. Compared with control interventions, metformin appears to be an effective intervention for overweight women with PCOS.
\end{abstract}

\section{Introduction}

Polycystic ovary syndrome (PCOS) is a common gynaecological endocrine disease in women of childbearing age [1]. PCOS is characterized by excessive androgens, persistent anovulation, infertility, and metabolic disorders [2]. The morbidity rate is $6 \%$ to $15 \%$ among women during the childbearing period, and to date, the cause is not completely clear. Extensive clinical and epidemiological data show that approximately $50 \%$ of PCOS patients are overweight or obese [3]. Overweight women with PCOS suffer more severe endocrine and metabolic disorders than nonoverweight patients [4]. Studies have found that being overweight enhances insulin secretion but weakens the metabolism of insulin secretion in the liver, skeletal muscle, and fat. In addition to impaired insulin responsiveness of adipocytes, being overweight may also cause lipodystrophy and insulin resistance by reducing the expression of lipid droplet proteins in adipocytes [5, 6]. Karimi et al. [7] and Heshmati et al. [8] suggest that patients with polycystic ovary syndrome 
generally have insulin resistance and elevated serum insulin and abnormal lipoprotein metabolism. Studies have shown that overweight women with PCOS have a higher risk of type 2 diabetes, hypertension, hyperlipidaemia, cardiovascular disease, and metabolic syndrome [9]. Metformin is a biguanide insulin sensitizer [10]. It does not affect insulin secretion but can improve insulin action [11]. It is a first-line drug for the treatment of type 2 diabetes (T2 DM) [12]. Its mechanism of action is to reduce blood lipid levels, reduce liver glucose production, stimulate the liver and skeletal muscles to perform insulin-mediated glucose uptake, and reduce the utilization of gluconeogenic substrates [13]. Obese women with PCOS exhibit metabolic characteristics similar to those with T2 DM in terms of insulin resistance and hyperinsulinemia [14]. Since 1994, metformin has been used as an insulin sensitizer for the treatment of polycystic ovary syndrome [15]. Studies have shown that metformin can not only improve endocrine disorders in patients with PCOS but also regulate ovarian function and even reduce the weight of overweight women with PCOS [16]. Heidari et al. [17] believe that metformin can improve endothelial function and endothelial dysfunction in women with PCOS, but it has limited effects in improving glucose metabolism and dyslipidemia. From the current research status, the therapeutic effect of metformin on PCOS patients is still controversial, especially for overweight PCOS patients. In this study, a meta-analysis was performed to compare the metabolic regulatory effect of metformin in overweight women with PCOS.

\section{Methods}

2.1. Research Strategy. This meta-analysis was planned, conducted, and reported according to the Preferred Reporting Items for Systematic Reviews and Meta-Analyses (PRISMA) recommendations. We searched the PubMed, Cochrane Library, Embase, CNKI, VIP, and Wanfang databases for studies published before March 2020. Search terms including free terms and Medical Subject Heading terms (MeSH). The search terms were ("Metformin" OR "Metformin Hydrochloride" OR "Hydrochloride Metformin" OR "Dimethylbiguanidine") AND ("polycystic ovary syndrome" OR "Stein-Leventhal Syndrome") and randomized controlled trials (RCTs). Additionally, the reference lists of retrieved publications were also reviewed to identify relevant papers that might be missed during electronic database search. Two independent reviewers selected and screened all results and, in cases where they disagreed, a third reviewer was asked for advice. The review applied the PRISMA statement guidelines for reporting systematic reviews and metaanalyses [18].

2.2. Eligibility Criteria. The inclusion criteria for this systematic review were as follows: (1) the study design was a randomized controlled trial (RCT) related to the effect of metformin on PCOS in overweight women; (2) recruit humans as subjects, and the subject's BMI $>25 \mathrm{~kg} / \mathrm{m}^{2}$; (3) metformin was listed as the main intervention in the experimental group and compared with the nonintervention control status; and (4) at least one metabolic parameter was reported, and data including the mean and standard deviation of each group at baseline and postintervention as well as the number of participants in each group were available. The exclusion criteria were as follows: (1) duplicate publications; (2) nonintervention designs (such as case-control studies, cohort studies, cross-sectional studies, case reports and experiences, theory research, and reviews); and (3) nonclinical tests and animal experiments.

2.3. Data Extraction. Two review authors independently screened the literature using the predetermined inclusion criteria and extracted data from the trials. The following information was extracted: participant characteristics, intervention and outcome data, adverse effects, and methodological quality. We resolved any disagreements about the extracted data from the included studies by consensus and consulted a third review author if disagreements persisted.

2.4. Risk of Bias Assessment. The risk of study bias was assessed using the Cochrane Handbook for Systematic Reviews. The risk of bias was evaluated with regard to the following aspects: generation of random sequences, allocation of hidden methods, application of the blinding method, incomplete results, selective reporting of results, and other bias. Funnel diagrams were used to detect publication bias.

\subsection{Statistical Analysis}

2.5.1. Extracting and Merging of Data. The Cochrane Collaboration's Review Manager 5.3 software was used to extract the relevant dichotomous or continuous data from the literature for analysis. Risk ratios (RRs) were calculated for dichotomous data, whereas the mean differences (MDs) and standard deviations (SDs) were calculated for continuous variables. The corresponding 95\% confidence intervals (CIs) and forest plots were used in both cases. In our metaanalysis, we used SDs when the data had the same units. When they had different units, we performed a conversion. The chi-squared and $I^{2}$ (inconsistency) tests were used to detect heterogeneity. A $p$ value $<.10$ or $I^{2}>50 \%$ indicated that there was significant heterogeneity. The fixed-effects model was used when $p>10$ and $I^{2}<50 \%$, and the randomeffects model was used when $p<10$ or $I^{2} \geq 50 \%$.

2.5.2. Data Conversion. The final values of body mass index (BMI), waist circumference (WC), follicle-stimulating hormone (FSH), homeostasis model assessment of insulin resistance (HOMA-IR), luteinizing hormone (LH), sex hormone-binding globulin (SHBG), high-density lipoprotein (HDL) cholesterol, low-density lipoprotein (LDL) cholesterol, total cholesterol (TC), triglycerides (TG), fasting blood glucose (FBG), fasting insulin, testosterone, and androstenedione were used as indicators to evaluate the efficacy of metformin in the intervention group and the control group. If the abovementioned metabolic indicators 
were not explicitly reported in the study, we calculated the mean value and SD of metabolic indicators with the following formulas:

(1) If the number of samples $(n)$ and the standard error (SE) were known, the SD was calculated as

$$
\mathrm{SD}=\mathrm{SE} \times \sqrt{n} .
$$

(2) Estimates of the SD were calculated if the number of samples $(n)$, mean, and 95\% CI [19-21] were known: "a" and " $\mathrm{b}$ " are the upper and lower confidence limits, respectively:

$$
\begin{aligned}
& \mathrm{SD}=\frac{a-\text { mean }}{1.96 \sqrt{n}}, \\
& \mathrm{SD}=\frac{\text { mean }-b}{1.96 \sqrt{n}} .
\end{aligned}
$$

\section{Results}

3.1. Study Selection. A total of 626 study reports were screened, 294 of which were excluded because they were duplicate publications. After reading the titles and abstracts, an additional 170 articles were excluded, and 162 articles were retained. Among them, 117 articles did not meet the inclusion criteria, 15 studies were improperly compared, and in 18 studies, we could not extract the data. Finally, twelve RCTs with a total of 683 participants were included. The PRISMA flow diagram is shown in Figure 1.

3.2. Study Characteristics. The principal study characteristics are summarized in Table 1. Twelve studies were published between 2002 and 2019. A total of 683 participants were included. The number of participants in the individual studies ranged from 9 to 74 . All of the included trials were single-center studies. The included studies came from different countries: United States [27], United Kingdom $[30,31]$, Iran [23, 28, 29], Brazil [22, 24], Italy [25, 27], India [32], and Turkey [33]. The duration of the intervention varied from 6 to 48 weeks. All participants had PCOS and a BMI $>25 \mathrm{~kg} / \mathrm{m}^{2}$. In the included studies, in the intervention group, the metformin intervention doses ranged from $750 \mathrm{mg}$ to $2000 \mathrm{mg}$.

3.3. Quality Assessment. Figure 2 provides an overview of the risk of bias for the included studies based on the tools provided by the Cochrane Manual. All included studies used a double-blind approach and reported dropouts. Most trials reported allocation concealment and random allocation but did not mention the specific method used. Five studies $[25-27,30,31]$ reported automatic generation of random sequences by a computer, while two studies $[23,28]$ reported that they divided participants into an experimental group and a control group by using random number tables. Selective reporting was unbiased but without any description to evaluate the existence of other biases. All the included trials reported whether adverse events occurred.

\subsection{Study Results}

3.4.1. BMI. Figure 3(a)shows the forest plots of the BMI analysis. The number of RCTs included was twelve. The combined results were statistically significant (WMD $=-1.25,95 \%$ CI $(-1.60,-0.91), p<0.00001)$. Compared with the control group, metformin had a positive effect on BMI in overweight women with PCOS. We used a fixedeffects model for the quantitative BMI data and showed low heterogeneity $\left(I^{2}=54 \%, p=0.01\right)$.

3.4.2. Waist Circumference. In terms of reducing waist circumference, there was a significant difference between the metformin group and the control group (WMD $=-1.41$, 95\% CI $(-2.46,-0.37), p=0.008$ ) (Figure 3(b)). There was substantial heterogeneity among the included studies $\left(I^{2}=81 \%, p<0.00001\right)$.

3.4.3. Fasting Insulin. The combined results of eight studies showed that overweight women with PCOS in the metformin group did not have significantly reduced fasting insulin $(\mathrm{WMD}=2.70,95 \% \mathrm{CI}(-15.95,21.33), p=0.78)$; these studies had low heterogeneity $\left(\mathrm{I}^{2}=56 \%, p=0.03\right)$ (Figure 3(c)).

3.4.4. Testosterone. Nine included trials including 458 participants [26, 31-33] reported data on changes in testosterone following metformin use. There was some heterogeneity in testosterone between overweight women with PCOS participating in the metformin intervention and those in the control group $\left(I^{2}=59 \%, p=0.01\right)$. Compared to the control group, the testosterone levels in the metformin group were reduced, and there were significant differences $(\mathrm{WMD}=-8.96,95 \%$ CI $(-12.30,-5.62), \quad p<0.00001)$ (Figure 3(d)).

\subsubsection{Study on the Comprehensive Efficacy of Metformin.} Studies investigated the effects of metformin on ten outcomes (FSH (follicle-stimulating hormone), HOMA-IR (homeostasis model assessment of insulin resistance), LH (luteinizing hormone), SHBG (sex hormone-binding globulin), HDL (high-density lipoprotein) cholesterol, LDL (low-density lipoprotein) cholesterol, TC (total plasma cholesterol), TG (triglycerides), FBG (fasting blood glucose), and androstenedione).

The synthesized results showed positive effects of metformin on $\mathrm{FSH}(\mathrm{WMD}=-0.49,95 \% \mathrm{CI}-0.85$ to -0.13 , $p=0.007, I^{2}=0 \%$; Figure 3(e)), LH (WMD $=-0.96,95 \% \mathrm{CI}$ -0.17 to $-0.22, p=0.01, I^{2}=95 \%$; Figure $\left.3(\mathrm{f})\right)$, and LDL cholesterol (WMD $=-12.10,95 \%$ CI 0.22 to $1.00, p=0.01$, $I^{2}=64 \%$; Figure $\left.3(\mathrm{~g})\right)$. There was not significant difference in HOMA-IR $(\mathrm{SMD}=0.29,95 \% \mathrm{CI}-0.61$ to $1.18, p=0.53$, $I^{2}=84 \%$; Figure 4(a)), SHBG (WMD $=-2.21,95 \% \mathrm{CI}-4.63$ to $0.20, p=0.007, \mathrm{I}^{2}=60 \%$; Figure $\left.4(\mathrm{~b})\right)$, HDL cholesterol $\left(\mathrm{WMD}=-0.70,95 \% \mathrm{CI}-1.83\right.$ to $0.42, p=0.22, \mathrm{I}^{2}=0 \%$; Figure $4(\mathrm{c}))$, TC $(\mathrm{WMD}=-0.10,95 \% \mathrm{CI}-0.35$ to 0.15 , $p=0.43, I^{2}=78 \%$; Figure $\left.4(\mathrm{~d})\right), \mathrm{TG}(\mathrm{WMD}=-0.02,95 \% \mathrm{CI}$ 


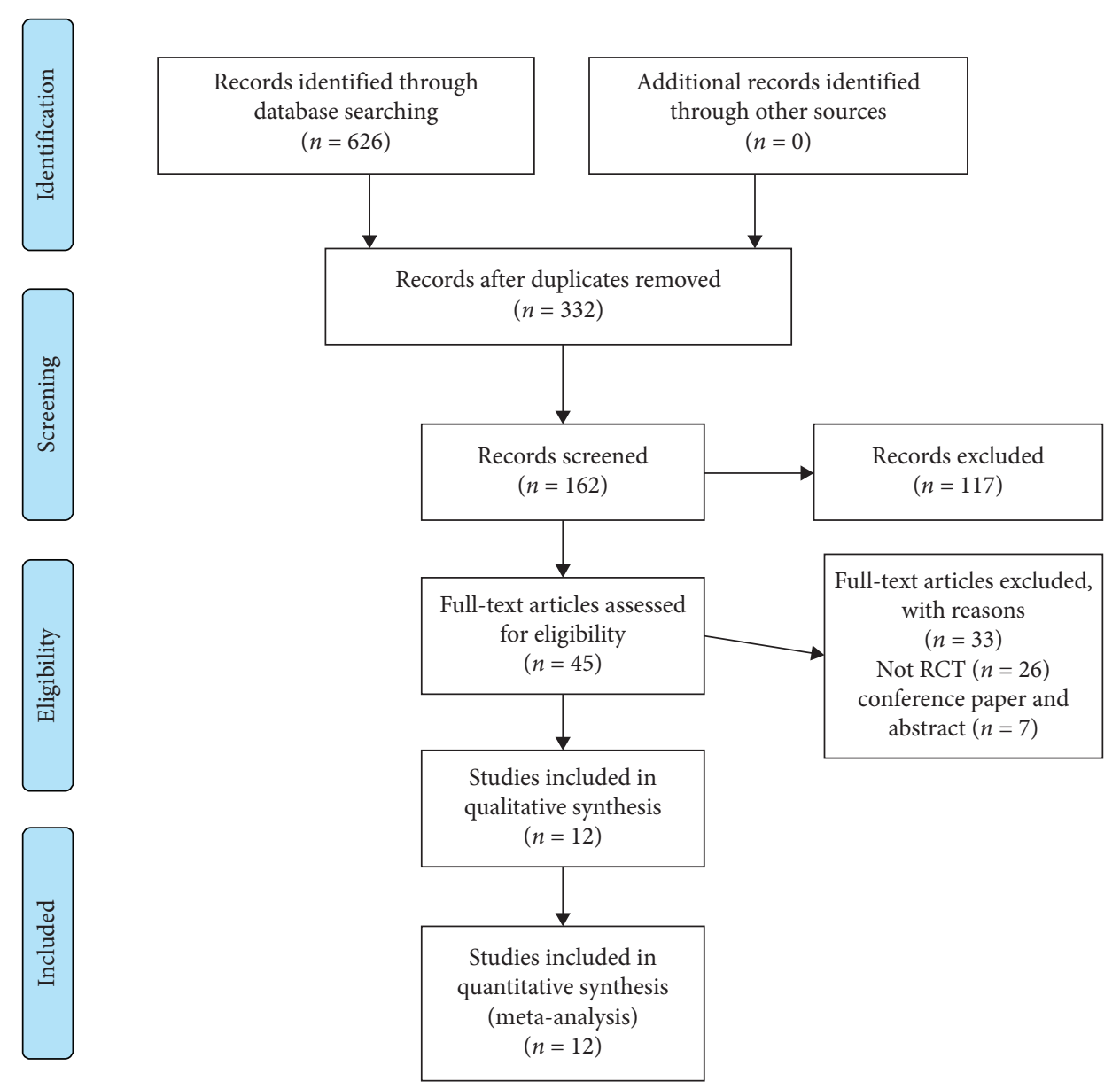

FIgURE 1: Study selection procedure according to the PRISMA statement.

-0.28 to $0.23, p=0.86, I^{2}=0 \%$; Figure $\left.4(\mathrm{e})\right)$, FBG (WMD $=-0.68,95 \% \mathrm{CI}-2.06$ to $0.07, p=0.34, I^{2}=41 \%$; Figure $4(\mathrm{f}))$, or androstenedione $(\mathrm{WMD}=-0.11,95 \% \mathrm{CI}$ -0.33 to $0.12, p=0.35, I^{2}=55 \%$; Figure $\left.4(\mathrm{~g})\right)$, between overweight women with PCOS who received a metformin intervention and those in the control group.

3.5. Publication Bias. The publication bias of the twelve RCTs was evaluated with a funnel plot. Figure 5 shows that the publication bias across the studies was small.

\section{Discussion}

Polycystic ovary syndrome (polycystic ovary syndrome, PCOS) is a gynaecological endocrine disorder commonly seen in women of reproductive age and has highly heterogeneous clinical manifestations [34]. Approximately $70 \%$ of PCOS patients are overweight or obese, and PCOS may be related to genetic, environmental factors including diet, lifestyle, and hormone levels [35]. Obesity as a risk factor often causes female diseases such as breast cancer [36]. Studies have found that, with increases in weight, abnormal genes such as the Wnt signalling pathway, oxidative stress, and inflammation in adipose tissue of PCOS patients are abnormal [37], suggesting that obesity participates in the pathogenesis of PCOS [38], triggers metabolic and reproductive disorders, and may also cause glycolipid metabolism, hyperandrogenaemia, menstrual disorders, infertility, and comorbidities related to polycystic ovary syndrome [39]. Furthermore, we also noticed that many features and complications of polycystic ovary syndrome (PCOS) can trigger oxidative stress and increase insulin resistance index $[40,41]$. Obese women with PCOS show lower ISOGTT and higher $\mathrm{LH}$ to stimulate androgen secretion, triggering insulin resistance and excessive androgens [42]. Current evidence-based guidelines recommend that overweight women with PCOS use metformin to control their weight and endocrine and metabolic disorders [43]. As the most widely used insulin sensitizer for PCOS, metformin can reduce liver glucose production, inhibit gluconeogenesis and adipogenesis, and improve peripheral tissue insulin sensitivity [44]. In addition, a large number of studies have shown that metformin can not only reduce weight and metabolic disorders but also correct menstrual patterns, restore ovulation, and even allow conception $[45,46]$. Furthermore, in previous systematic reviews, the specific therapeutic effect of metformin on metabolic indicators in overweight women 
International Journal of Endocrinology

5

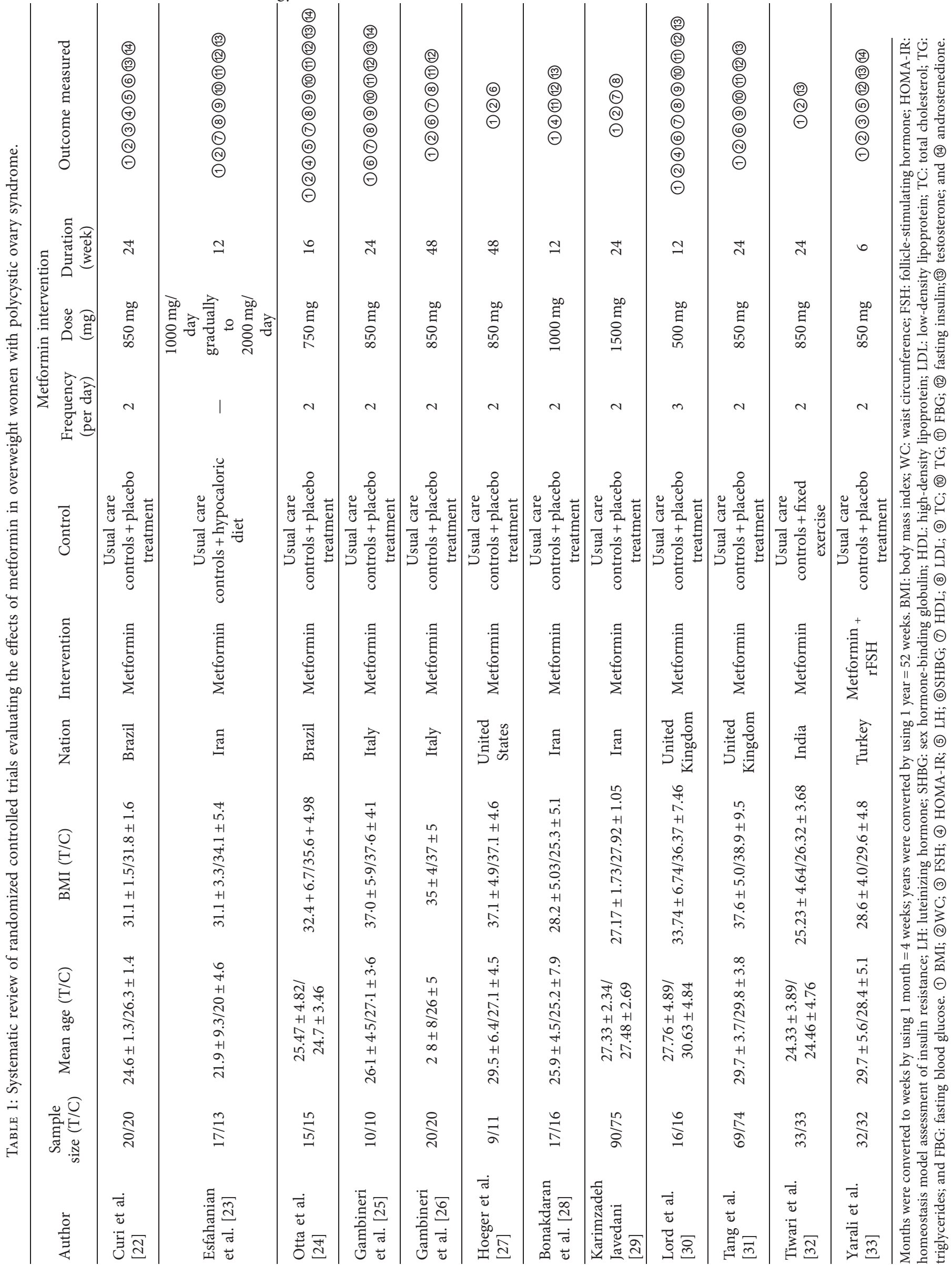




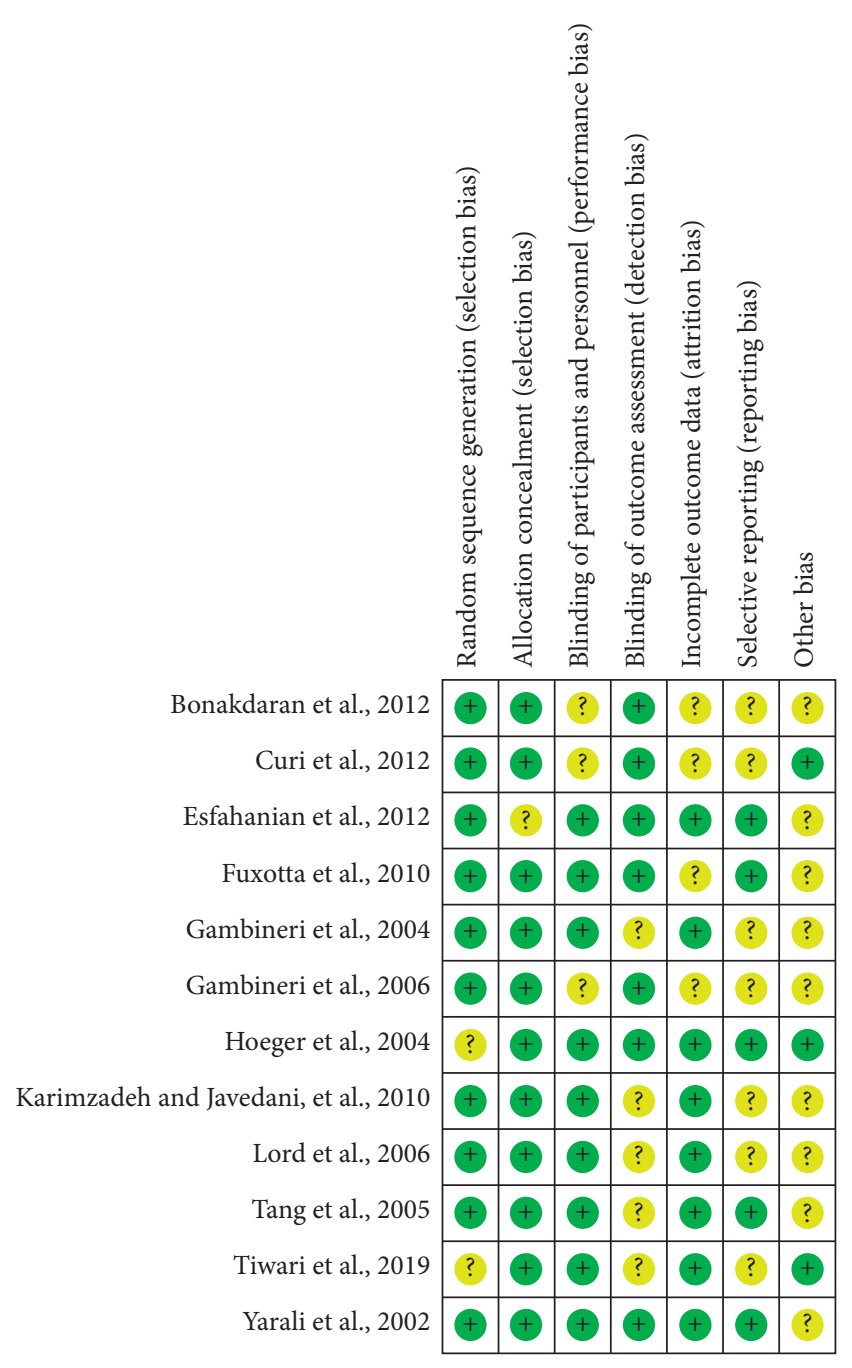

FIGURE 2: Risk of bias summary: review of authors' judgements about each risk of bias item for each included study.

with PCOS has not been evaluated. Through quantitative synthesis, we found that as a drug that regulates the metabolism of overweight women with PCOS, metformin seems to have a partial effect, can reduce BMI and WC, and can reduce testosterone, FSH, LH, and LDL cholesterol.

4.1. Summary of the Main Results. Combined with our research results, we found that taking metformin can reduce body mass index, waist circumference, FSH, LH, LDL cholesterol, and testosterone levels in overweight women with PCOS. However, there was no improvement in fasting insulin levels, HOMA-IR, LDL cholesterol levels, HDL cholesterol levels, SHBG levels, FBG levels, androstenedione levels, TC levels, or TG levels. Our current results suggest that metformin may be the most effective intervention for PCOS in overweight women [47]. The results show that the improvement of body mass index, waist circumference, and LDL cholesterol may be the direct regulation effect of metformin on the production of ovarian steroids $[11,48]$. Our research results found that metformin has a lowering effect on FSH in overweight PCOS patients. It can be considered as abnormal gonadotrophic secretion in women with overweight PCOS, which makes FSH in an abnormal secretion stage [49]. The antireproductive effect of metformin helps correct this phenomenon [50]. The production of polycystic ovary syndrome is directly related to the abnormality of insulin. Insulin resistance will cause hyperinsulinemia, which directly affects the role of ovarian receptors, inhibits insulinbinding protein and sex hormone-binding protein, while freeing testosterone and increasing ovarian androgens. Therefore, metformin is used to regulate insulin secretion and achieve the purpose of effectively improving polycystic ovary syndrome. This finding is consistent with international guidelines for the management of overweight and diseased adults and overweight people. Most approved weight management drugs are contraindicated in women of reproductive age, but metformin has fewer side effects, is safer, and is recommended for use in PCOS treatment [51]. Clinical studies of overweight women with PCOS have found that endocrine disorders can lead to infertility [52]. This study found that metformin has a certain regulatory effect on PCOS sex hormones in overweight women, can promote luteinizing hormone secretion, achieve ovulation, and improve the menstrual cycle of patients. In addition, it has the function of regulating follicle-stimulating hormone secretion. Some studies have suggested that the abnormal state of ovarian ultrasound detection in patients with polycystic ovary syndrome is closely related to testosterone levels [53]. Studies have also confirmed that reduced testosterone levels can effectively improve the hyperandrogenaemia of PCOS in overweight women and improve clinical symptoms such as excess hair, black acanthosis, and acne [54].

4.2. Limitations. This study has several limitations. First, in some cases, we had to calculate and transform data rather than data being provided directly. Second, the study distribution between the twelve RCTs was included, which may affect the meta-analysis results. The results of the included studies showed significant differences, which may be due to the different metformin doses, durations, center settings, and selected populations of different treatment programs. We performed a sensitivity analysis of the included RCTs and found that two studies may be a source of most of the heterogeneity. In both studies, different laboratory tests were used, which may have an impact on the comprehensive measurement results. In addition, language, publication bias, and not being registered with PROSPERO limit our research. Finally, this review only included randomized controlled trials. In the future, there is a need for a greater diversity of research, such as cooperation between multiple centres, more rigorous clinical reports, and prospective studies.

4.3. Clinical Implications. We summarize the current research status of metformin in overweight women with PCOS and provide data to support future PCOS clinical trials. Although this study shows that metformin can effectively regulate the levels of BMI and physiological function indicators in overweight PCOS women, more clinical studies are needed in the future to prove that effective prevention can reduce the occurrence of complications (such as hypertension and stroke) [55, 56]. This result should be 


\begin{tabular}{|c|c|c|c|c|c|c|c|c|c|c|c|c|}
\hline \multirow{3}{*}{$\begin{array}{l}\text { Study or subgroup } \\
\text { Bonakdaran et al., } 2012\end{array}$} & \multicolumn{3}{|c|}{ Experimental } & \multirow{3}{*}{$\begin{array}{c}\text { Mean } \\
25.3\end{array}$} & \multirow{3}{*}{$\begin{array}{c}\begin{array}{c}\text { Control } \\
\text { SD }\end{array} \\
5\end{array}$} & \multirow{3}{*}{$\begin{array}{c}\text { Total } \\
16\end{array}$} & \multirow{3}{*}{$\begin{array}{c}\text { Weight (\%) } \\
1.2\end{array}$} & \multirow{3}{*}{$\begin{array}{l}\text { Mean difference } \\
\text { IV, fixed, } 95 \% \text { CI }\end{array}$} & \multirow{2}{*}{\multicolumn{4}{|c|}{$\begin{array}{l}\text { Mean difference } \\
\text { IV, fixed, } 95 \% \text { CI }\end{array}$}} \\
\hline & \multirow{2}{*}{$\begin{array}{c}\text { Mean } \\
26.2\end{array}$} & \multirow{2}{*}{$\begin{array}{l}\mathrm{SD} \\
4.23\end{array}$} & \multirow{2}{*}{$\begin{array}{c}\text { Total } \\
17\end{array}$} & & & & & & & & & \\
\hline & & & & & & & & & & & & \\
\hline Curi et al., 2012 & 30.2 & 0.8 & 20 & 30.1 & 1.5 & 20 & 21.2 & $0.10(-0.65,0.85)$ & & - & - & \\
\hline Esfahanian et al., 2012 & 32.29 & 3.19 & 17 & 31.15 & 5.45 & 13 & 1.1 & $1.14(-2.19,4.47)$ & & & & \\
\hline Fuxotta et al., 2010 & 31.53 & 4.98 & 15 & 34.16 & 4.95 & 15 & 0.9 & $-2.63(-6.18,0.92)$ & & & - & \\
\hline Gambineri et al., 2004 & 34.1 & 6 & 10 & 35.4 & 4 & 10 & 0.6 & $-1.30(-5.77,3.17)$ & & & & \\
\hline Gambineri et al., 2006 & 33 & 5 & 20 & 35 & 5 & 20 & 1.2 & $-2.00(-5.10,1.10)$ & & & — & \\
\hline Hoeger et al., 2004 & 37.9 & 4.1 & 9 & 39.7 & 7.1 & 11 & 0.5 & $-1.80(-6.78,3.18)$ & & & & \\
\hline Karimzadeh and Javedani, et al., 2010 & 25.17 & 1.73 & 90 & 26.92 & 1.05 & 75 & 63.7 & $-1.75(-2.18,-1.32)$ & & 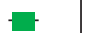 & & \\
\hline Lord et al., 2006 & 34.6 & 9.13 & 16 & 35.26 & 6.53 & 16 & 0.4 & $-0.66(-6.16,4.84)$ & & & & \\
\hline Tang et al., 2005 & 37.1 & 5.04 & 69 & 37.4 & 6.3 & 74 & 3.4 & $-0.30(-2.16,1.56)$ & & 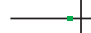 & - & \\
\hline Tiwari et al., 2019 & 24.16 & 4.37 & 33 & 25.86 & 3.59 & 33 & 3.2 & $-1.70(-3.63,0.23)$ & & $\longrightarrow$ & & \\
\hline Yarali et al., 2002 & 28 & 3.4 & 32 & 29.8 & 4.9 & 32 & 2.7 & $-1.80(-3.87,0.27)$ & & & - & \\
\hline Total $(95 \%$ CI $)$ & & & 348 & & & 335 & 100.0 & $-1.25(-1.60,0.91)$ & & & & \\
\hline $\begin{array}{l}\text { Heterogeneity: chi }{ }^{2}=23.95, d f=11(P \\
\text { Test for overall effect: } Z=7.16(P<0.0\end{array}$ & $\begin{array}{l}=0.01) \\
0001)\end{array}$ & $I^{2}=54$ & & & & & & & -4 & $\begin{array}{ll}-2 & 0\end{array}$ & 2 & 4 \\
\hline & & & & & & & & & Favours (exp & imental) & Favour & control) \\
\hline
\end{tabular}

(a)

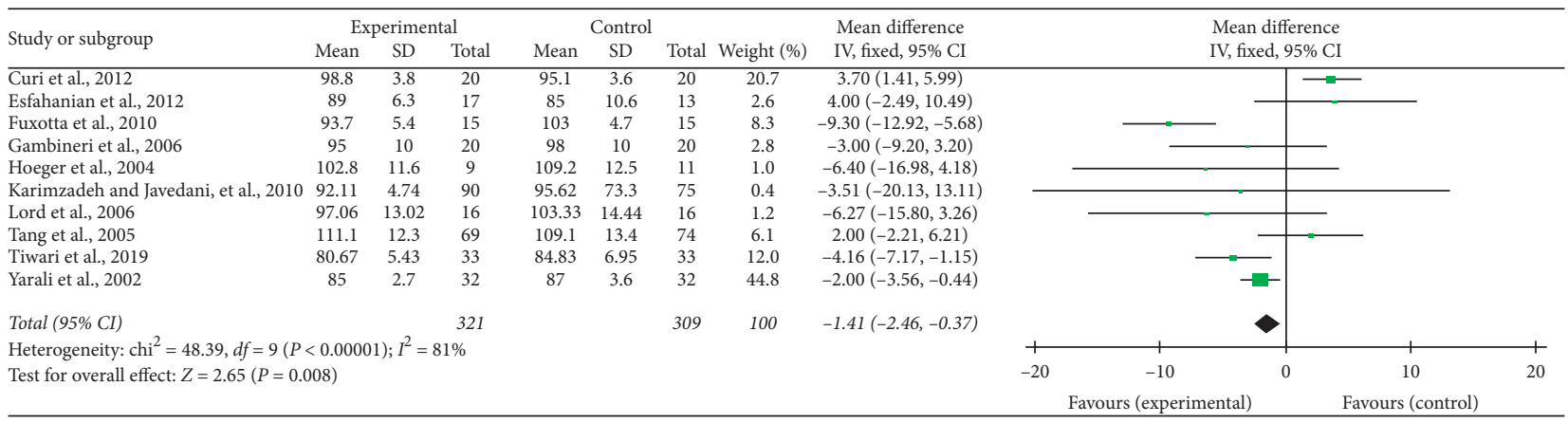

(b)

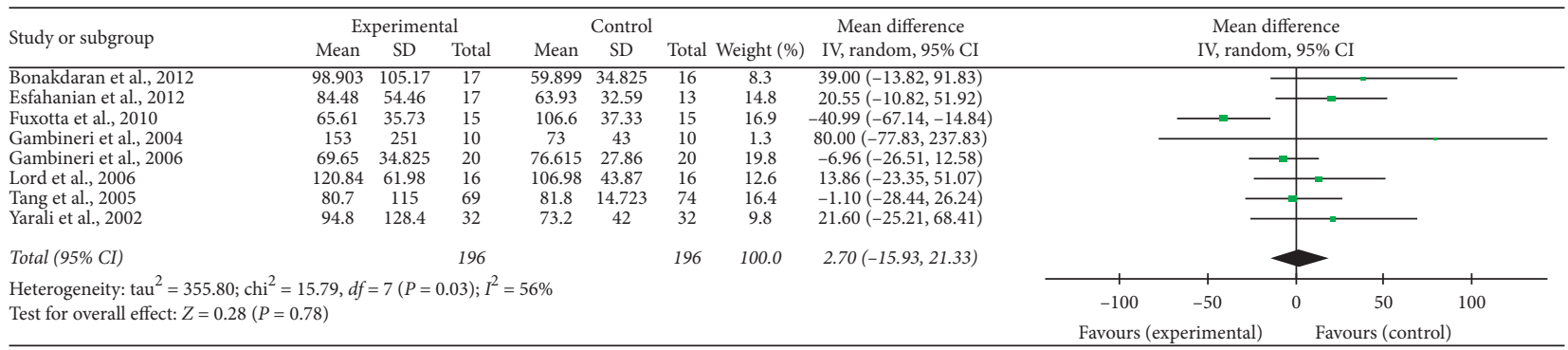

(c)

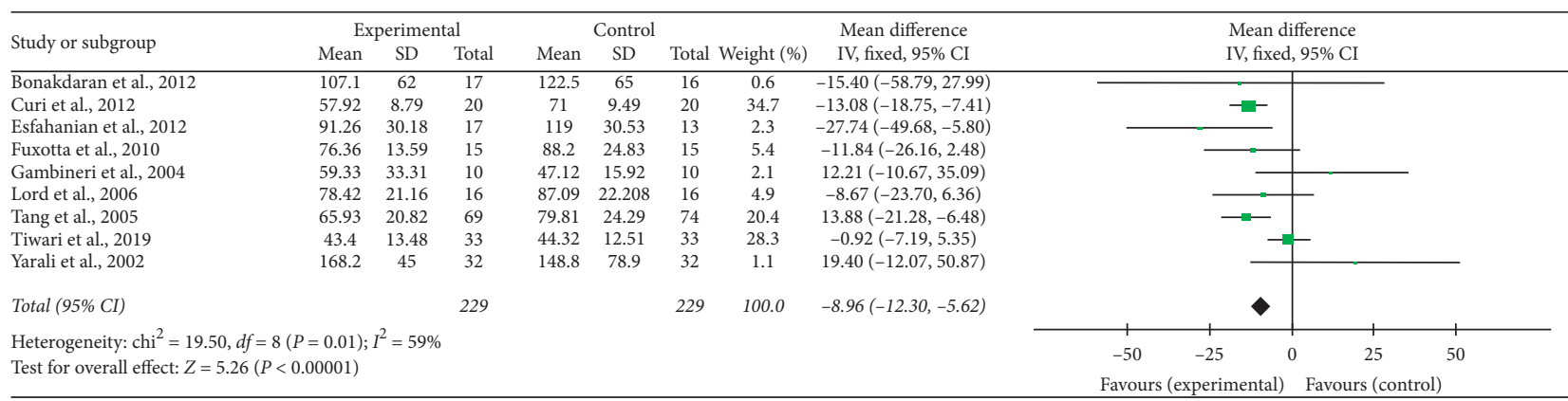

(d)

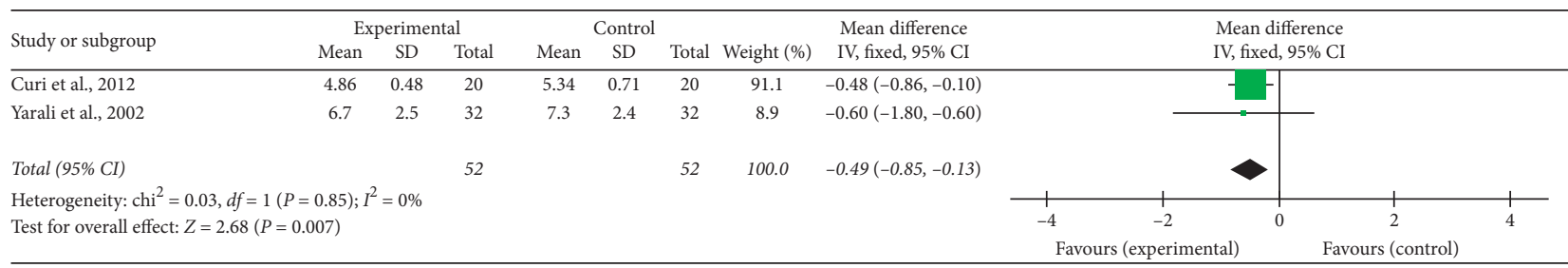

(e)

Figure 3: Continued. 


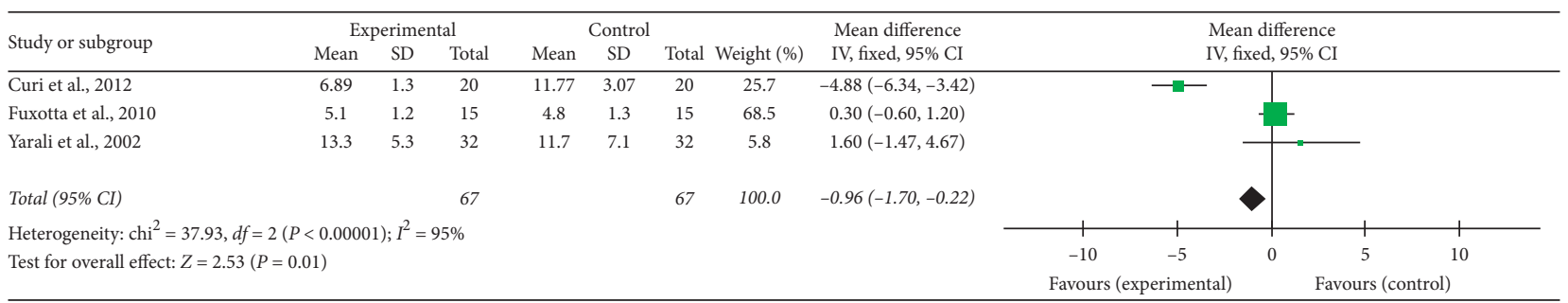

(f)

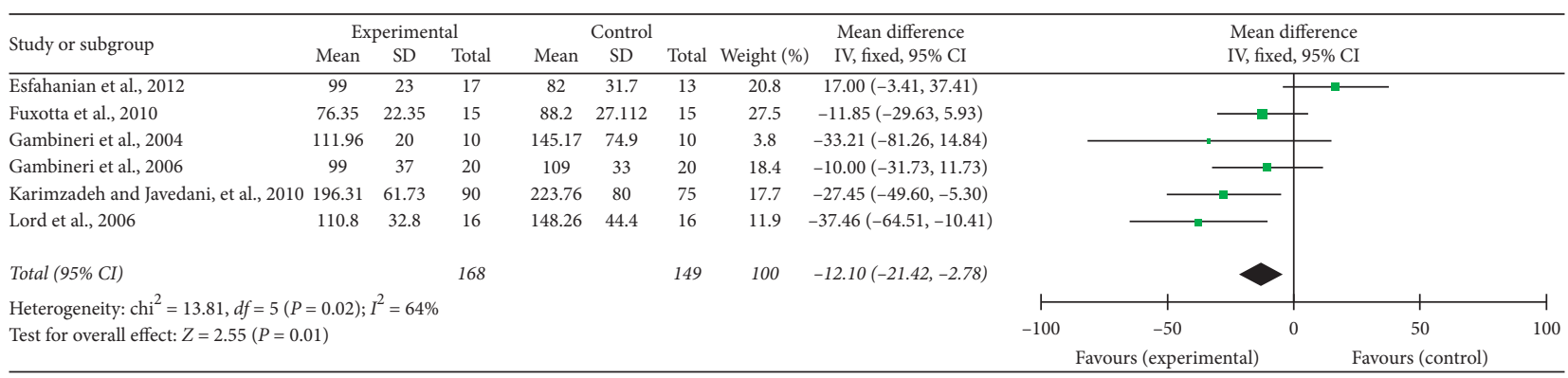

$(\mathrm{g})$

Figure 3: Effect of metformin on (a) body mass index; (b) waist circumference; (c) fasting insulin; (d) testosterone; (e) follicle-stimulating hormone; (f) luteinizing hormone; and (g) low-density lipoprotein.

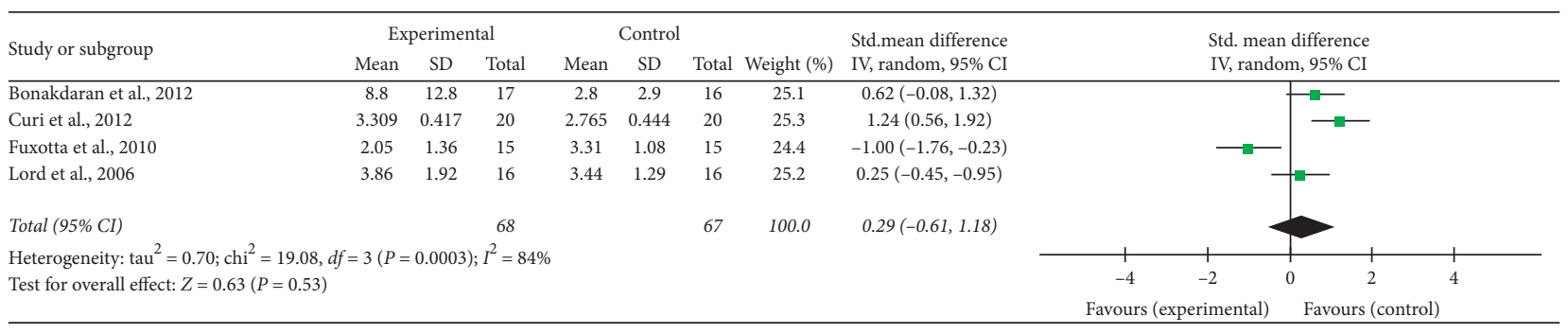

(a)

\begin{tabular}{|c|c|c|c|c|c|c|c|c|c|c|c|c|}
\hline \multirow{3}{*}{$\begin{array}{l}\text { Study or subgroup } \\
\text { Curi et al., } 2012\end{array}$} & \multicolumn{3}{|c|}{ Experimental } & \multicolumn{3}{|c|}{ Control } & \multirow{3}{*}{ Weight (\%) } & \multirow{3}{*}{$\begin{array}{c}\text { Mean difference } \\
\text { IV, fixed, 95\% CI } \\
-7.99(-12.26,-3.72)\end{array}$} & \multirow{2}{*}{\multicolumn{4}{|c|}{$\begin{array}{l}\text { Mean difference } \\
\text { IV, fixed, } 95 \% \mathrm{CI}\end{array}$}} \\
\hline & \multirow{2}{*}{$\begin{array}{c}\text { Mean } \\
28.41\end{array}$} & \multirow{2}{*}{$\begin{array}{l}\mathrm{SD} \\
3.9\end{array}$} & \multirow{2}{*}{$\frac{\text { Total }}{20}$} & \multirow{2}{*}{$\frac{\text { Mean }}{36.4}$} & \multirow{2}{*}{$\begin{array}{c}\mathrm{SD} \\
8.94\end{array}$} & \multirow{2}{*}{$\begin{array}{c}\text { Total } \\
20\end{array}$} & & & & & & \\
\hline & & & & & & & & & & -n- & & \\
\hline Gambineri et al., 2004 & 19 & 16 & 10 & 19 & 16 & 10 & 3.0 & $0.00(-14.02,14.02)$ & & & & \\
\hline Gambineri et al., 2006 & 22.1 & 12.5 & 20 & 22.6 & 17.9 & 20 & 6.4 & $-0.50(-10.07,9.07)$ & & & & \\
\hline Hoeger et al., 2004 & 31.6 & 11.7 & 9 & 25.7 & 11.4 & 11 & 5.6 & $5.90(-4.29,16.09)$ & & - & & \\
\hline Lord et al., 2006 & 27.41 & 9.98 & 16 & 30.27 & 9.35 & 16 & 13.0 & $-2.86(-9.56,3.84)$ & & & - & \\
\hline Tang et al., 2005 & 22.1 & 11.4 & 69 & 21.1 & 11.8 & 74 & 40.2 & $1.00(-2.80,4.80)$ & & - & - & \\
\hline Total $(95 \%$ CI $)$ & & & 144 & & & 151 & 100.0 & $-2.21(-4.63,0.20)$ & & & & \\
\hline Heterogeneity: $\mathrm{chi}^{2}=1$ & 3); $I^{2}=($ & & & & & & & & & 1 & & + \\
\hline Test for overall effect: $Z$ & & & & & & & & & -20 & -10 & 10 & 20 \\
\hline & & & & & & & & & Favours (exp & rimental) & Favours & control) \\
\hline
\end{tabular}

(b)

Figure 4: Continued. 


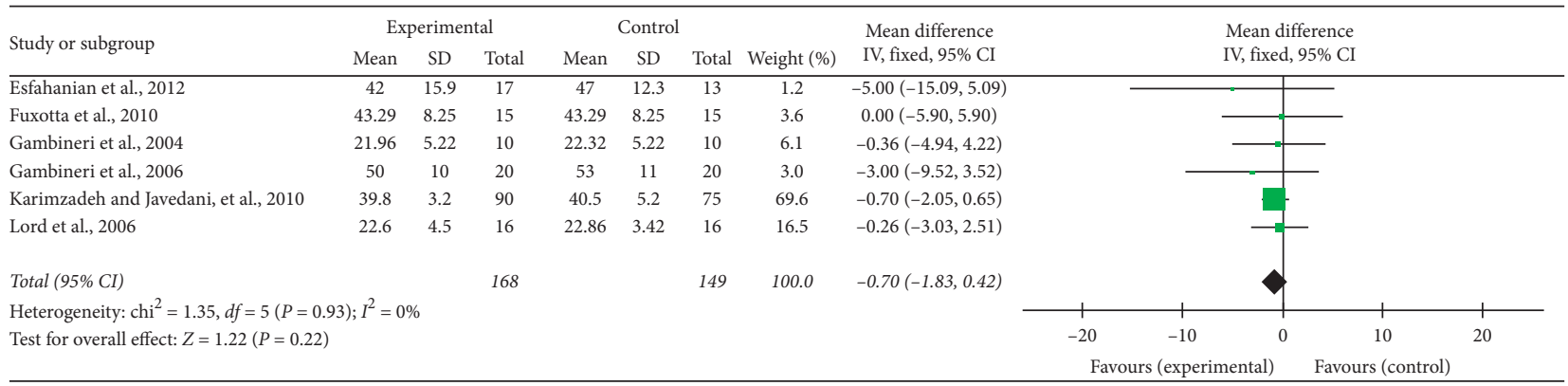

(c)

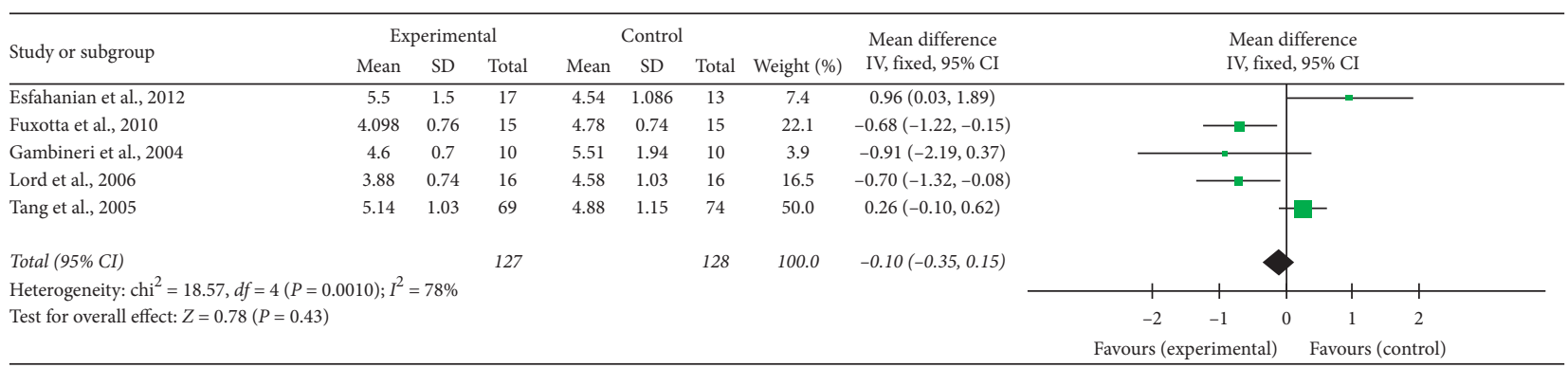

(d)

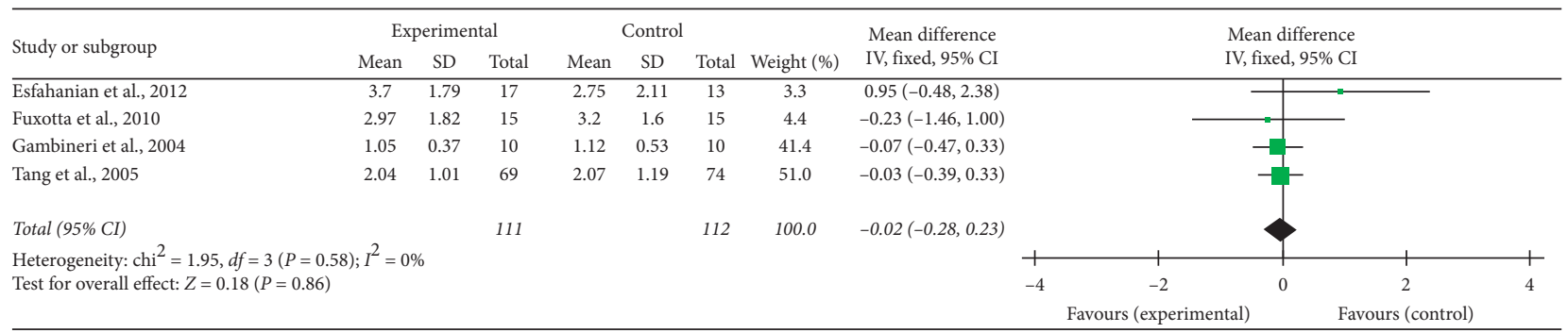

(e)

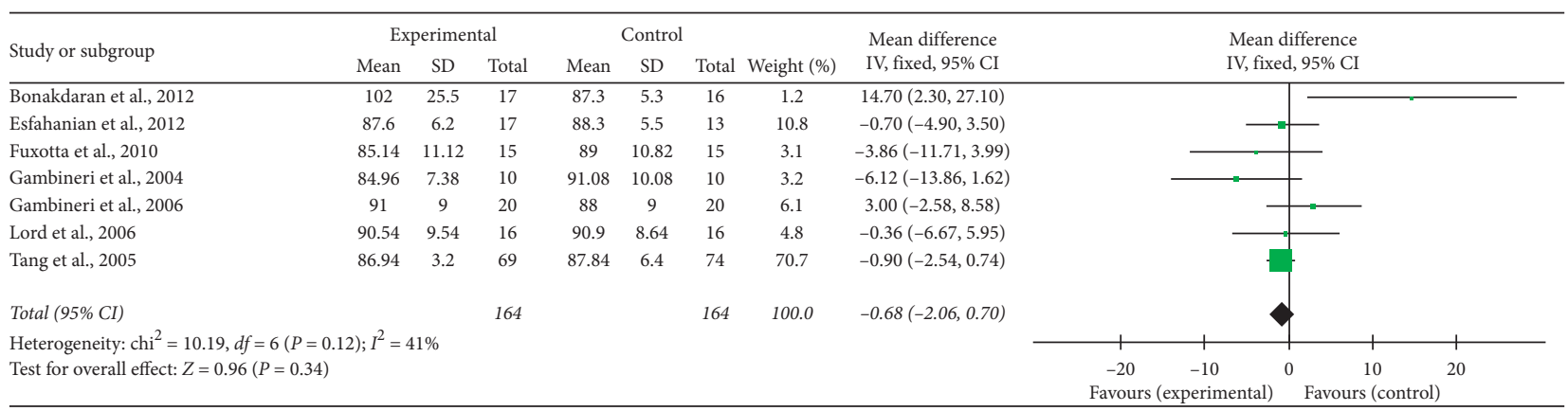

(f)

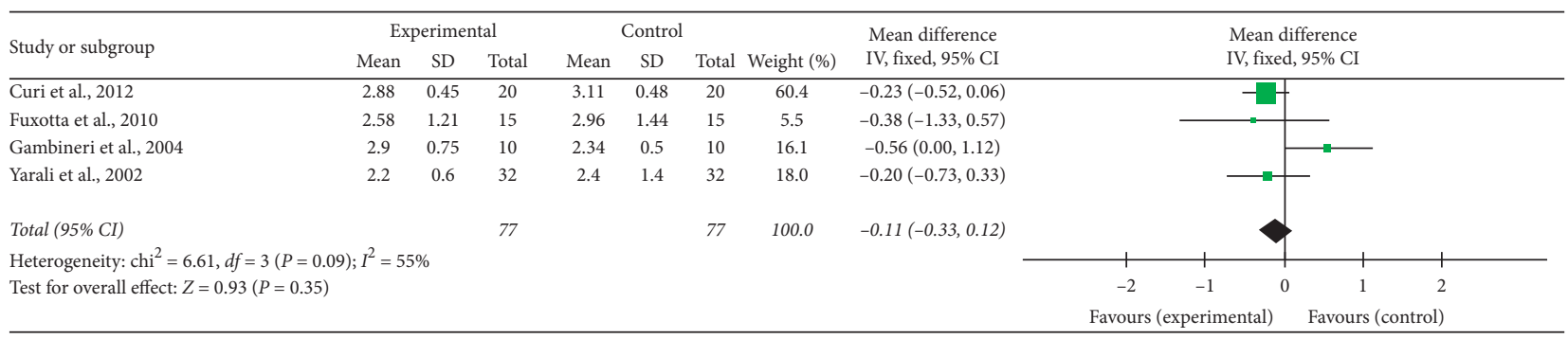

(g)

FIGURE 4: Effect of metformin on (a) homeostasis model assessment of insulin resistance; (b) sex hormone-binding globulin; (c) highdensity lipoprotein; (d) total plasma cholesterol; (e) triglycerides; (f) fasting blood glucose; and (g) androstenedione. 


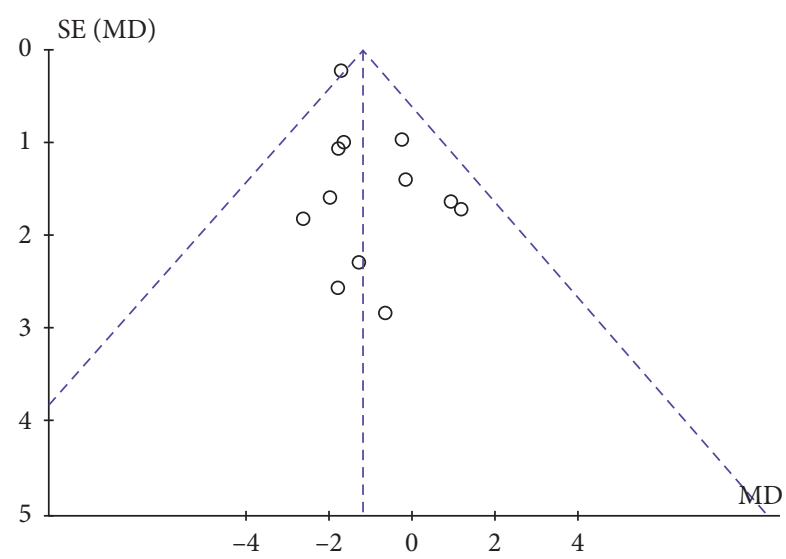

FIGURE 5: Funnel plot of publication bias.

interpreted with caution due to the insufficient quality of current evidence research methods and the observed clinical heterogeneity. In future studies, further attention should be paid to the effects of metformin dosage and intervention time in overweight women with PCOS. In conclusion, this study found that metformin has a certain regulatory effect on the relevant physiological indicators of overweight women with PCOS.

\section{Conclusion}

Compared with control interventions, metformin appears to be an effective intervention for overweight women with PCOS. We have to admit that this study may have some serious limitations. Different treatment options, doses, duration, and enrolment of different populations may have led to obvious heterogeneity, and we need to interpret the results carefully. More RCTs with a rigorous research design are needed to determine the efficacy of metformin in treating PCOS patients, to evaluate the risk factors in overweight women, and to apply metformin in interventions for nonoverweight PCOS patients to prevent or treat the occurrence of PCOS and its complications.

\section{Abbreviations}

CI: $\quad$ Confidence interval

CNKI: China National Knowledge Infrastructure

MD: $\quad$ Mean difference

PRISMA: Preferred Reporting Items Systematic Reviews and Meta-Analyses

PubMed: National Library of Medicine

RCT: $\quad$ Randomized controlled trial

RR: $\quad$ Risk ratio

SD: $\quad$ Standard deviation

SE: $\quad$ Standard error

VIP: $\quad$ VIP Database for Chinese Technical Periodicals

WMD: Weighted mean difference

PCOS: Polycystic ovary syndrome

BMI: $\quad$ Body mass index

WC: Waist circumference

FSH: Follicle-stimulating hormone
HOMA- Homeostasis model assessment of insulin

IR: resistance

LH: $\quad$ Luteinizing hormone

SHBG: Sex hormone-binding globulin

TG: $\quad$ Triglycerides

TC: $\quad$ Total cholesterol

HDL: High-density lipoprotein

LDL: Low-density lipoprotein

FBS: $\quad$ Fasting blood glucose.

\section{Data Availability}

All the data in this paper support the results of this study.

\section{Conflicts of Interest}

The authors declare no conflicts of interest.

\section{Authors' Contributions}

Yuanyuan Guan and Hongwu Wang conceptualized the study; Yuanyuan Guan contributed to data curation; Yuanyuan Guan contributed to formal analysis; Yuanyuan Guan and Huaien $\mathrm{Bu}$ investigated the study; Yuanyuan Guan, Tieniu Zhao, and Hongwu Wang contributed to methodology; Hongwu Wang, Huaien Bu, and Tieniu Zhao were responsible for project administration; Yuanyuan Guan provided software; Hongwu Wang supervised the study; Yuanyuan Guan wrote and prepared the original draft; and Yuanyuan Guan and Dongjun Wang wrote, reviewed, and edited the manuscript.

\section{Acknowledgments}

The authors gratefully acknowledge the support from the National Key Research and Development Program of China (approval no. 2017YFC1703305) and the Basic Research on Health Identification of Traditional Chinese Medicine in Tianjin Colleges and Universities "Innovation Team Training Plan" (approval no. TD13-5049) during the 13th Five-Year Plan period.

\section{Supplementary Materials}

PRISMA checklist used in the study. (Supplementary Materials)

\section{References}

[1] R. S. Legro, S. A. Arslanian, D. A. Ehrmann et al., "Diagnosis and treatment of polycystic ovary syndrome: an endocrine society clinical practice guideline," The Journal of Clinical Endocrinology \& Metabolism, vol. 98, no. 12, pp. 4565-4592, 2013.

[2] R. J. Norman, D. Dewailly, R. S. Legro, and T. E. Hickey, "Polycystic ovary syndrome," The Lancet, vol. 370, no. 9588, pp. 685-697, 2007.

[3] L. Mu, Y. Zhao, R. Li, Y. Lai, and J. Qiao, "Metabolic characteristics of normal weight central obesity phenotype polycystic ovary syndrome women: a large-scale national 
epidemiological survey," Reproductive Biomedicine Online, vol. 37, no. 4, pp. 498-504, 2018.

[4] S. Arya, K. R. Hansen, and R. A. Wild, "Metformin, rosiglitazone, or both for obese women with polycystic ovary syndrome?" Fertility and Sterility, vol. 113, no. 1, pp. 87-88, 2020.

[5] B. Shi, D. Feng, M. Sagnelli et al., "Fructose levels are elevated in women with polycystic ovary syndrome with obesity and hyperinsulinemia," Human Reproduction, vol. 35, pp. 187194, 2020.

[6] M. P. Czech, "Insulin action and resistance in obesity and type 2 diabetes," Nature Medicine, vol. 23, no. 7, pp. 804-814, 2017.

[7] E. Karimi, J. Heshmati, N. Shirzad et al., "The effect of synbiotics supplementation on anthropometric indicators and lipid profiles in women with polycystic ovary syndrome: a randomized controlled trial," Lipids in Health and Disease, vol. 19, p. 60, 2020.

[8] J. Heshmati, F. Farsi, S. Yosaee et al., "The effects of probiotics or synbiotics supplementation in women with polycystic ovarian syndrome: a systematic review and meta-analysis of randomized clinical trials," Probiotics and Antimicrobial Proteins, vol. 11, no. 4, pp. 1236-1247, 2019.

[9] N. M. Rashad, Y. S. Saraya, S. A. Afifi, A. E. Ali, and R. M. Alsayed, "Impact of weight loss on plasma ghrelin level, clinical, and metabolic features of obese women with or without polycystic ovary syndrome," Middle East Fertility Society Journal, vol. 24, 2019.

[10] W. L. Bennett, H. E. Aschmann, M. A. Puhan et al., "A benefitharm analysis of adding basal insulin vs. sulfonylurea to metformin to manage type II diabetes mellitus in people with multiple chronic conditions," Journal of Clinical Epidemiology, vol. 113, pp. 92-100, 2019.

[11] P. Moghetti, R. Castello, C. Negri et al., "Metformin effects on clinical features, endocrine and metabolic profiles, and insulin sensitivity in polycystic ovary syndrome: a randomized, double-blind, placebo-controlled 6-month trial, followed by open, long-term clinical evaluation," The Journal of Clinical Endocrinology \& Metabolism, vol. 85, no. 1, pp. 139-146, 2000.

[12] B. Viollet, B. Guigas, N. S. Garcia, J. Leclerc, M. Foretz, and F. Andreelli, "Cellular and molecular mechanisms of metformin: an overview," Clinical Science, vol. 122, no. 5-6, pp. 253-270, 2012.

[13] M. O. Goodarzi and M. Bryer-Ash, "Metformin revisited: reevaluation of its properties and role in the pharmacopoeia of modern antidiabetic agents," Diabetes, Obesity and Metabolism, vol. 7, no. 6, pp. 654-665, 2005.

[14] F. Cirillo, C. Catellani, P. Lazzeroni et al., "MiRNAs regulating insulin sensitivity are dysregulated in polycystic ovary syndrome (PCOS) ovaries and are associated with markers of inflammation and insulin sensitivity," Frontiers in Endocrinology, vol. 10, 2019.

[15] E. M. Velazquez, S. Mendoza, T. Hamer, F. Sosa, and C. J. Glueck, "Metformin therapy in polycystic ovary syndrome reduces hyperinsulinemia, insulin resistance, hyperandrogenemia, and systolic blood pressure, while facilitating normal menses and pregnancy," Metabolism, vol. 43, no. 5, pp. 647-654, 1994.

[16] K. K. Blomquist, V. A. Milsom, R. D. Barnes et al., "Metabolic syndrome in obese men and women with binge eating disorder: developmental trajectories of eating and weight-related behaviors," Comprehensive Psychiatry, vol. 53, no. 7, pp. 1021-1027, 2012.

[17] B. Heidari, A. Lerman, A. Z. Lalia, L. O. Lerman, and A. Y. Chang, "Effect of metformin on microvascular endothelial function in polycystic ovary syndrome," Mayo Clinic Proceedings, vol. 94, no. 12, pp. 2455-2466, 2019.

[18] D. Moher, A. Liberati, J. Tetzlaff, and D. G. Altman, "Preferred reporting items for systematic reviews and meta-analyses: the PRISMA statement," International Journal of Surgery, vol. 8, no. 5, pp. 336-341, 2010.

[19] S. P. Hozo, B. Djulbegovic, and I. Hozo, "Estimating the mean and variance from the median, range, and the size of a sample," BMC Medical Research Methodology, vol. 5, p. 13, 2005.

[20] X. Wan, W. Wang, J. Liu, and T. Tong, "Estimating the sample mean and standard deviation from the sample size, median, range and/or interquartile range," BMC Medical Research Methodology, vol. 14, p. 135, 2014.

[21] Y. P. Xu, Y. Y. Yu, and W. J. Fu, "Introduction of methods for estimating standardized mean difference when missing standard deviation conversion in meta-analysis," Chinese Journal of Evidence-Based Cardiovasc Medicine, vol. 8, no. 12, pp. 14121415, 2016.

[22] D. D. G. Curi, A. M. Fonseca, J. A. M. Marcondes et al., "Metformin versus lifestyle changes in treating women with polycystic ovary syndrome," Gynecological Endocrinology, vol. 28, no. 3, pp. 182-185, 2012.

[23] F. Esfahanian, M. M. Zamani, R. Heshmat, and F. Moini nia, "Effect of metformin compared with hypocaloric diet on serum C-reactive protein level and insulin resistance in obese and overweight women with polycystic ovary syndrome," Journal of Obstetrics and Gynaecology Research, vol. 39, no. 4, pp. 806-813, 2013.

[24] C. F. Otta, M. Wior, G. S. Iraci et al., "Clinical, metabolic, and endocrine parameters in response to metformin and lifestyle intervention in women with polycystic ovary syndrome: a randomized, double-blind, and placebo control trial," Gynecological Endocrinology, vol. 26, pp. 173-178, 2010.

[25] A. Gambineri, C. Pelusi, S. Genghini et al., "Effect of flutamide and metformin administered alone or in combination in dieting obese women with polycystic ovary syndrome," Clinical Endocrinology, vol. 60, no. 2, pp. 241-249, 2004.

[26] A. Gambineri, L. Patton, A. Vaccina et al., "Treatment with flutamide, metformin, and their combination added to a hypocaloric diet in overweight-obese women with polycystic ovary syndrome: a randomized, 12-month, placebo-controlled study," The Journal of Clinical Endocrinology \& Metabolism, vol. 91, no. 10, pp. 3970-3980, 2006.

[27] K. M. Hoeger, L. Kochman, N. Wixom, K. Craig, R. K. Miller, and D. S. Guzick, "A randomized, 48-week, placebo-controlled trial of intensive lifestyle modification and/or metformin therapy in overweight women with polycystic ovary syndrome: a pilot study," Fertility and Sterility, vol. 82, no. 2, pp. 421-429, 2004.

[28] S. Bonakdaran, Z. Mazloom Khorasani, B. Davachi, and J. Mazloom Khorasani, "The effects of calcitriol on improvement of insulin resistance, ovulation and comparison with metformin therapy in PCOS patients: a randomized placebo- controlled clinical trial," Iranian Journal of Reproductive Medicine, vol. 10, no. 5, pp. 465-472, 2012.

[29] M. A. Karimzadeh and M. Javedani, "An assessment of lifestyle modification versus medical treatment with clomiphene citrate, metformin, and clomiphene citrate-metformin in patients with polycystic ovary syndrome," Fertility and Sterility, vol. 94, no. 1, pp. 216-220, 2010.

[30] J. Lord, R. Thomas, B. Fox, U. Acharya, and T. Wilkin, "The effect of metformin on fat distribution and the metabolic syndrome in women with polycystic ovary syndrome-a 
randomised, double-blind, placebo-controlled trial," BJOG: An International Journal of Obstetrics and Gynaecology, vol. 113, no. 7, pp. 817-824, 2006.

[31] T. Tang, J. Glanville, C. J. Hayden, D. White, J. H. Barth, and A. H. Balen, "Combined lifestyle modification and metformin in obese patients with polycystic ovary syndrome. A randomized, placebo-controlled, double-blind multicentre study," Human Reproduction, vol. 21, no. 1, pp. 80-89, 2006.

[32] N. Tiwari, S. Pasrija, and S. Jain, "Randomised controlled trial to study the efficacy of exercise with and without metformin on women with polycystic ovary syndrome," European Journal of Obstetrics \& Gynecology and Reproductive Biology, vol. 234, pp. 149-154, 2019.

[33] H. Yarali, B. O. Yildiz, A. Demirol et al., "Co-administration of metformin during rFSH treatment in patients with clomiphene citrate-resistant polycystic ovarian syndrome: a prospective randomized trial," Human Reproduction, vol. 17, no. 2, pp. 289-294, 2002.

[34] A. Neven, J. Laven, H. Teede, and J. Boyle, "A summary on polycystic ovary syndrome: diagnostic criteria, prevalence, clinical manifestations, and management according to the latest international guidelines," Seminars in Reproductive Medicine, vol. 36, no. 01, pp. 005-012, 2018.

[35] S. S. Lim, M. J. Davies, R. J. Norman, and L. J. Moran, "Overweight, obesity and central obesity in women with polycystic ovary syndrome: a systematic review and metaanalysis," Human Reproduction Update, vol. 18, no. 6, pp. 618-637, 2012.

[36] N. Namazi, P. Irandoost, J. Heshmati, B. Larijani, and L. Azadbakht, "The association between fat mass and the risk of breast cancer: a systematic review and meta-analysis," Clinical Nutrition, vol. 38, no. 4, pp. 1496-1503, 2019.

[37] G. D. Chazenbalk, J. D. Phan, V. Madrigal, X. Ding, X. Li, and D. A. Dumesic, "Abnormal expression of genes governing adipogenesis and extracellular matrix (ecm) formation IN subcutaneous (SC) abdominal adipose stem cells (ASCS) OF lean polycystic ovary syndrome (PCOS) women," Fertility and Sterility, vol. 104, no. 3, p. E20, 2015.

[38] L. Tang, L. Yuan, G. Yang et al., "Changes in whole metabolites after exenatide treatment in overweight/obese polycystic ovary syndrome patients," Clinical Endocrinology, vol. 91, no. 4, pp. 508-516, 2019.

[39] Z. Shaaban, A. Khoradmehr, A. Amiri-Yekta, M. R. Jafarzadeh Shirazi, and A. Tamadon, "Pathophysiologic mechanisms of obesity- and chronic inflammation-related genes in etiology of polycystic ovary syndrome," Iranian Journal of Basic Medical Sciences, vol. 22, no. 12, pp. 1378-1386, 2019.

[40] J. Heshmati, F. Golab, M. Morvaridzadeh et al., "The effects of curcumin supplementation on oxidative stress, Sirtuin-1 and peroxisome proliferator activated receptor $\gamma$ coactivator $1 \alpha$ gene expression in polycystic ovarian syndrome (PCOS) patients: a randomized placebo-controlled clinical trial," Diabetes \& Metabolic Syndrome: Clinical Research \& Reviews, vol. 14, no. 2, pp. 77-82, 2020.

[41] J. Heshmati, R. Omani-Samani, S. Vesali et al., "The effects of supplementation with chromium on insulin resistance indices in women with polycystic ovarian syndrome: a systematic review and meta-analysis of randomized clinical trials," Hormone and Metabolic Research, vol. 50, no. 03, pp. 193-200, 2018.

[42] E. Diamanti-Kandarakis and A. Dunaif, "Insulin resistance and the polycystic ovary syndrome revisited: an update on mechanisms and implications," Endocrine Reviews, vol. 33, no. 6, pp. 981-1030, 2012.
[43] H. J. Teede, M. L. Misso, M. F Costello et al., "Recommendations from the international evidence-based guideline for the assessment and management of polycystic ovary syndrome," Human Reproduction (Oxford, England), vol. 33, no. 9, pp. 1602-1618, 2018.

[44] J. A. Rowan, W. M. Hague, W. Gao, M. R. Battin, M. P. Moore, and G. T. I. Mi, "Metformin versus insulin for the treatment of gestational diabetes," New England Journal of Medicine, vol. 358, no. 19, pp. 2003-2015, 2008.

[45] E. Fraison, L. Moran, S. Bilal, C. Ee, C. Venetis, and M. Costello, "Metformin versus the combined oral contraceptive pill for hirsutism, acne, and menstrual pattern in polycystic ovary syndrome," Human Reproduction, vol. 34, p. 458, 2019.

[46] E. M. Bordewijk, M. Nahuis, M. F. Costello et al., "Metformin during ovulation induction with gonadotrophins followed by timed intercourse or intrauterine insemination for subfertility associated with polycystic ovary syndrome," Cochrane Database of Systematic Reviews, vol. 1, no. 1, 2017.

[47] C. M. Apovian, L. J. Aronne, D. H. Bessesen et al., "Pharmacological management of obesity: an endocrine Society clinical practice guideline," The Journal of Clinical Endocrinology \& Metabolism, vol. 100, no. 2, pp. 342-362, 2015.

[48] D. Kurzthaler, D. Hadziomerovic-Pekic, L. Wildt, and B. E. Seeber, "Metformin induces a prompt decrease in LHstimulated testosterone response in women with PCOS independent of its insulin-sensitizing effects," Reproductive Biology and Endocrinology, vol. 12, no. 1, p. 98, 2014.

[49] Y. Li, C. Chen, Y. Ma et al., "Multi-system reproductive metabolic disorder: significance for the pathogenesis and therapy of polycystic ovary syndrome (PCOS)," Life Sciences, vol. 228, pp. 167-175, 2019.

[50] C. J. Glueck, A. Moreira, N. Goldenberg, L. Sieve, and P. Wang, "Pioglitazone and metformin in obese women with polycystic ovary syndrome not optimally responsive to metformin," Human Reproduction, vol. 18, no. 8, pp. 1618-1625, 2003.

[51] B. C. Tarlatzis, B. Fauser, and E. A.-S. Thessaloniki, "Consensus on infertility treatment related to polycystic ovary syndrome," Human Reproduction, vol. 23, pp. 462-477, 2008.

[52] M. Hickey, D. A. Doherty, H. Atkinson et al., "Clinical, ultrasound and biochemical features of polycystic ovary syndrome in adolescents: implications for diagnosis," Human Reproduction, vol. 26, no. 6, pp. 1469-1477, 2011.

[53] J. Münzker, D. Hofer, C. Trummer et al., "Testosterone to dihydrotestosterone ratio as a new biomarker for an adverse metabolic phenotype in the polycystic ovary syndrome," The Journal of Clinical Endocrinology \& Metabolism, vol. 100, no. 2, pp. 653-660, 2015.

[54] T. Semlitsch, F. L. Stigler, K. Jeitler, K. Horvath, and A. Siebenhofer, "Management of overweight and obesity in primary care-A systematic overview of international evidence-based guidelines," Obesity Reviews, vol. 20, no. 9, pp. 1218-1230, 2019.

[55] S. Lattanzi, M. Bartolini, L. Provinciali, and M. Silvestrini, "Glycosylated hemoglobin and functional outcome after acute ischemic stroke," Journal of Stroke and Cerebrovascular Diseases, vol. 25, no. 7, pp. 1786-1791, 2016.

[56] S. Lattanzi, F. Brigo, F. Vernieri, and M. Silvestrini, "Visit-tovisit variability in blood pressure and Alzheimer's disease," The Journal of Clinical Hypertension, vol. 20, no. 5, pp. 918924, 2018. 